\title{
Comparación de dos métodos de extracción de ADN a partir de hojas secas de guayaba (Psidium guajava L.) para estudios moleculares
}

\section{Comparison of two methods of DNA extraction from dried guava leaves (Psidium guajava L.) for molecular studies}

\author{
Enrique Pardo-Pérez ${ }^{1}$; José Luis Coronado-González²; Mauricio Begambre-Hernández ${ }^{3}$
}

\begin{abstract}
'Lic. en Biología-Química, M.Sc., Ph.D. Universidad de Córdoba. Montería - Córdoba, Colombia; e-mail: epardop@correo.unicordoba.edu.co; (D) https:// orcid.org/0000-0002-6467-5790

²Biólogo. Universidad de Córdoba. Montería, Córdoba, Colombia; e-mail: jcoronadogonzalez@correo.unicordoba.edu.co; (D) https://orcid.org/0000-00028532-800X
\end{abstract}

${ }^{3}$ Biólogo. Universidad de Córdoba. Montería - Córdoba, Colombia; e-mail: mbegambre@correo.unicordoba.edu.co; (D) https://orcid.org/0000-0002-20323996

Cómo citar: Pardo-Pérez, E.; Coronado-González, J.L.; Begambre-Hernández, M. 2021. Comparación de dos métodos de extracción de ADN a partir de hojas secas de guayaba (Psidium guajava L.) para estudios moleculares. Rev. U.D.C.A Act. \& Div. Cient. $24(1): e 1504$. http://doi.org/10.31910/rudca.v24.n1.2021.1504

Artículo de acceso abierto publicado por Revista U.D.C.A Actualidad \& Divulgación Científica, bajo una licencia Creative Commons CC BY-NC 4.0

Publicación oficial de la Universidad de Ciencias Aplicadas y Ambientales U.D.C.A, Institución de Educación Superior Acreditada de Alta Calidad por el Ministerio de Educación Nacional.

Recibido: marzo 22 de $2020 \quad$ Aceptado: diciembre 12 de 2020 Editado por: Ingeborg Zenner de Polanía

\section{INTRODUCCIÓN}

Teniendo en cuenta que en el último siglo se viene presentando un incremento en el detrimento de la diversidad genética en los cultivos agrícolas y de la biodiversidad de los ecosistemas naturales (Angarita et al. 2017), se hace necesario concretar esfuerzos para la preservación de los recursos fitogenéticos de este importante recurso, que ocupa en Colombia, el tercer lugar con mayor demanda interna y el séptimo, de mayor producción (Asohofrucol, 2019).

Buena parte de los protocolos existentes, para aislar y purificar DNA de buena calidad, se basan en la técnica del bromuro de cetiltrimetilamonio (CTAB), por ser económico (Sahu et al. 2012). También existen en el mercado kits comerciales para la extracción de $\mathrm{ADN}$, convenientes para obtener $\mathrm{ADN}$ de plantas, pero con mayores costos económicos (Whitehouse \& Hottel, 2007), que se diferencian en rendimiento de ADN, tipo y cantidad de muestra, tecnología de aislamiento y volumen de elución; deben ser adecuados para la extracción de múltiples muestras y producir exiguos residuos perjudiciales (Pipan et al. 2018).

Las hojas de guayaba contienen compuestos polifenólicos, flavonoides (Camarena-Tello et al. 2018), ácidos fenólicos y ácidos hidroxicinámicos (Narváez-Cuenca et al. 2020). Los fenólicos y los polisacáridos, se unen o coprecipitan con los ácidos nucleicos (Azmat et al. 2012), lo cual, puede acarrear al deterioro, a la contaminación y al bajo rendimiento del ADN (Sika et al. 2015). Nerdo et al. (2004) reportan éxito parcial en dos de los ocho métodos que utilizaron para extraer el ADN de las hojas jóvenes de guayaba, al igual que Kumari et al. (2018) y Kumar et al. (2020). 
Cuando se trabaja en lugares apartados y no se dispone de lo necesario para congelar las muestras, éstas deben ser deshidratadas, utilizando gel de sílice. La obtención de ácidos nucleicos de tejidos vegetales secos, se suele dificultar, ya que la mayoría de los protocolos están estandarizados para trabajar con muestras frescas (Kumari et al. 2018 y Kumar et al. 2020). Ante esto, el presente estudio tuvo como objetivo la comparación de dos métodos de extracción de ADN, a partir de hojas secas de Psidium guajava L.

\section{MATERIALES Y MÉTODOS}

Obtención del material vegetal. Se colectaron hojas en fase madura de 10 árboles de guayaba, ubicados en el campus central de la Universidad de Córdoba ( $8^{\circ} 47^{\prime} 31.0^{\prime \prime} \mathrm{N}$ y 7551'45.0” W), las cuales, se colocaron en una bolsa pequeña resellable, que tenía, previamente, sílica gel y, después, almacenadas a temperatura ambiente.

Obtención del ADN. Se evaluaron dos metodologías de extracción: el comercial Kit de extracción Wizard Genomic de Promega ${ }^{\circledR}$ (USA, Promega A1120) (Kit Promega) y el Mini-prep de Doyle \& Doyle (1987) modificado (MMpD\&D). En el primero, se siguieron las recomendaciones del fabricante y para el segundo método, se realizaron las siguientes modificaciones: se reemplazó el octanol por alcohol isoamílico, se redujo la centrifugación a 13.000 los rpm y se realizó la precipitación del ADN, con una solución de etanol absoluto + acetato de sodio en reemplazo del isopropanol.

Visualización del ADN. Se utilizó una electroforesis en gel de agarosa al 1\% (p/v), utilizando TBE 1X teñido con Gel-Red 30X, que se visualizaron en un transiluminador DyNA Light ${ }^{\mathrm{TM}} \mathrm{UV}$ (Labnet International Inc.) y documentados, mediante el fotodocumentador ENDUROTM GDS (Labnet International Inc.).

Cuantificación del ADN. El ADN obtenido fue cuantificado en un espectrofotómetro Colibri Microvolume Spectrometer (TitertekBerthold, Berthold Detection Systems GmbH, Bleichstrasse, Pforzheim, Germany), se estimó la pureza del ADN, por medio de la relación de absorbancia (A260/A280nm).

Evaluación de la calidad del ADN. Se realizó mediante los marcadores $m P g C I R 03, m P g C I R 16, m P g C I R 09$ y mPgCIR19 (Risterucci et al. 2005). La reacción en cadena de la polimerasa (PCR), se desarrolló en un volumen final de $25 \mu \mathrm{L}$, que contenían $1 \mathrm{U}$ de de Taq polimerasa (Thermo Scientific, Uklam-USA), 10pM de cada primer (forward y reverse), $0,2 \mathrm{mM}$ de dNTPs, buffer de PCR 1X (GIBCO-BRL, Groningen, Netherlands), 2,5mM de $\mathrm{MgCl}$,
$20 \mathrm{ng} / \mu \mathrm{L}$ de ADN y agua estéril, hasta alcanzar el volumen final. El programa empleado es: $95^{\circ} \mathrm{C}, 3 \mathrm{~min} ; 95^{\circ} \mathrm{C}, 30 \mathrm{~s} ; 45^{\circ} \mathrm{C}, 30 \mathrm{~s} ; 72^{\circ} \mathrm{C}$, $2 \mathrm{~min}$, con repetición de 40 ciclos del paso 2 al 4 y un paso final de extensión de $72^{\circ} \mathrm{C}, 10 \mathrm{~min}$. La PCR, se realizó en un termociclador Bioard T100 \#1861096 (Los Ángeles, USA).

Amplificación del ADN. Para la verificación de cada producto PCR obtenido, se prepararon geles de agarosa al 1\% $(\mathrm{p} / \mathrm{v})$, teñido con el reactivo GelRedTM, las cuales, se corrieron en una cámara de electroforesis horizontal Mini-Sub® Cell GT Bio-Rad SF1704467 (Los Ángeles, USA), a $100 \mathrm{~V}$ y $50 \mathrm{~mA}$ por 40 minutos. Los geles, se visualizaron en un Transiluminador DyNA Light UV (Labnet International Inc., Cary, North Carolina, USA); los registros, se tomaron en un Fotodocumentador ENDURO ${ }^{\mathrm{TM}}$ GDS (Labnet International Inc., Cary, North Carolina, USA).

Análisis estadístico. Se utilizó el software SPSS para Windows, versión 17.0 (SPSS Inc., 2008). Para cada uno de los métodos de extracción, se calcularon las medias y las desviaciones estándar (s). Para identificar el método que presenta diferencias significativas en la concentración y calidad de ADN, se utilizaron las pruebas de Tukey y Dunnet (Miller, 1996). Para el análisis de las amplificaciones de los marcadores, se comprobó la proporción de éxito, mediante la prueba de Chi-cuadrado (Halos et al. 2004).

\section{RESULTADOS Y DISCUSIÓN}

Los resultados del presente estudio mostraron la eficacia del MMpD\&D al compararlo con el Kit Promega, en cuanto a la extracción, pureza y rendimiento del ADN obtenido y mejora lo reportado por otros autores para la misma especie, quienes extrajeron ADN de hojas frescas de guayaba. Los resultados del análisis de absorbancia mostraron una concentración promedio de ADN en las muestras tratadas con el MMpD\&D de 9,76ng/ $\mu \mathrm{L}$ (s 2,028); asimismo, para la pureza del $\mathrm{ADN}$, el valor obtenido en la relación A260/A280 fue 1,8 (s 0,128), mientras la concentración promedio de ADN obtenido con el Kit Promega fue 155,9ng/ $\mu \mathrm{L}$ (s 91,8), mientras para la pureza del ADN el valor obtenido en la relación A260/A280 fue 1,12 (s 0,04) (Tabla 1).

Los ADN obtenidos mediante el kit Promega, se mostraron pegajosos, viscosos, oscuros, lo cual, indicaría la presencia de polifenoles de elevada densidad, que se co-purifican con el ADN, afectando la calidad del ácido nucleico obtenido (Deshmukh et al. 2007); además, Rojas et al. (2011) afirman que el color oscuro del pellet final evidencia la contaminación. Mediante el MMpD\&D, se obtuvo un ADN

Tabla 1. Concentración y pureza del ADN de hojas secas de Psidium guajava L. obtenido con los protocolos utilizados.

\begin{tabular}{|c|c|c|}
\hline Concentración y pureza & Kit Promega & Método Mini-prep \\
\hline \multirow{2}{*}{ Índice de calidad 260/280 } & \multicolumn{2}{|c|}{$\mu( \pm \mathrm{s})$} \\
\cline { 2 - 3 } & $1,12(0,04)$ & $1,8(0,128)$ \\
\hline $\mathrm{ADN}(\mathrm{ng} / \mu \mathrm{L})$ & $155,9(91,8)$ & $9,76(2,028)$ \\
\hline
\end{tabular}


incoloro, mostrando que se logró separar en el ADN componentes, como proteínas, polisacáridos y polifenoles. De igual forma, para la extracción de $\mathrm{ADN}$, se puede adicionar el acetato de sodio por su utilidad para separar polisacáridos (Michiels et al. 2003).

Si bien las cantidades de ADN obtenidos en los dos métodos utilizados reveló una menor concentración de ADN al utilizar el MMpD\&D respecto al Kit Promega (Tabla 1), estos valores sugieren que durante la extracción hay pérdida de ADN por factores, como la maceración con nitrógeno líquido, ya que al romperse las membranas los componentes celulares son liberados y la acción de polifenoles hace que gran parte del ADN se degrade o precipite con ellos (Cota et al. 2006). Los resultados revelaron que el MMpD\&D presentó un mayor nivel de pureza de 1,8 en comparación con el Kit Promega, que mostró valores de 1,12 (Tabla 1). Según Gerstein (2001), un ADN puro y de calidad debe estar en un rango de 1,7 a 2,0, para la relación de absorbancias 260/280; valores mayores a 2,0 indican la presencia de ARN y valores menores a 1,7, contaminación con proteínas.

Al aplicar la prueba de Tukey, los resultados obtenidos en la concentración de $\mathrm{ADN}$ en ambos métodos mostraron diferencias significativas, lo cual, indica que, en ambos casos, no fue posible obtener buena cantidad de ADN. Al comparar los resultados mediante la prueba de Dunett, se encontraron diferencias significativas y mayores concentraciones de ADN para el método Kit de Promega (Tabla 1); se encontraron diferencias en cuanto a la relación A260/ A280. Es importante resaltar que la relación A260/A280 fue de 1,12 (Tabla 1) para el método comercial, sugiriendo la probable presencia de contaminantes, tales como proteínas (Manning, 1991), mientras dicha relación fue de 1,8 para el MMpD\&D, obteniéndose así un ADN puro y de calidad.

Como se observa en la tabla 2, el mayor porcentaje de éxito en la amplificación, se obtuvo con el MMpD\&D para los marcadores $m P g C I R 16$ y mPgCIR19 (100\%), seguido por el marcador mPgCIR03 $(90 \%)$ y el marcador mPgCIR09 (80\%). Los resultados obtenidos con el Kit de Promega, no mostraron amplificaciones, produjo ADN de mala calidad para obtener productos de PCR, lo cual, se pudo deber a que el ADN pudiera presentar contaminantes o bien se ha degradado; resultado similar a lo expresado por Ferreira \& Grattapaglia (1998), quienes expresaron que la presencia de metabolitos secundarios en el ADN, inhiben la acción de la Taq polimerasa.

Tabla 2. Eficiencia de amplificación de los protocolos de extracción de ADN evaluados.

\begin{tabular}{|c|c|c|c|}
\hline \multirow{2}{*}{ Locus } & Protocolos evaluados & Número de Amplificaciones & Porcentaje de Amplificación \\
\hline \multirow{2}{*}{$m$ PgCIR03 } & $\mathrm{A}$ & 0 & $0 \%$ \\
\cline { 2 - 4 } & $\mathrm{B}$ & 9 & $90 \%$ \\
\hline \multirow{2}{*}{$m$ PgCIR16 } & $\mathrm{A}$ & 0 & $0 \%$ \\
\cline { 2 - 4 } & $\mathrm{B}$ & 10 & $100 \%$ \\
\hline \multirow{2}{*}{$m$ PgCIR09 } & $\mathrm{A}$ & 0 & $0 \%$ \\
\cline { 2 - 4 } & $\mathrm{B}$ & 8 & $80 \%$ \\
\hline \multirow{2}{*}{$m P g C I R 19$} & $\mathrm{~A}$ & 0 & $0 \%$ \\
\cline { 2 - 4 } & $\mathrm{B}$ & 10 & $100 \%$ \\
\hline
\end{tabular}

A: Kit de extracción Wizard de Promega ${ }^{\circledR}$; B: Mini-prep modificado.

Las modificaciones realizadas al MMpD\&D para la extracción de DNA de $P$. guajava permitieron optimizar un protocolo para obtener DNA de buena calidad y cantidad, a partir de hojas secas; obtener mayor calidad en la pureza y la integridad del DNA y la total amplificación de los marcadores moleculares utilizados.

Agradecimientos. La presente investigación, se realizó gracias al financiamiento de la Universidad de Córdoba, mediante el proyecto FCB -17-08. Conflicto de intereses: El manuscrito fue preparado y revisado con la participación de todos los autores, quienes declaran que no existe conflicto de interés que pondría en peligro la validez de los resultados presentados.

\section{REFERENCIAS}

1. ANGARITA, M; TORRES, M.I.; DÍAZ, A.K. 2017. Técnicas de Biología Molecular en el desarrollo de la investigación. Revisión de la literatura. Revista Habanera de Ciencias Médicas. (Cuba). 16(5):796-807

2. ASOCIACIÓN HORTIFRUTÍCOLA COLOMBIANA, ASOHOFRUCOL. 2019. Balance del sector hortifrutícola de Colombia en 2019. Disponible desde Internet en: http://www.asohofrucol.com.co/index.php (con acceso $12 / 08 / 2020)$. 
3. AZMAT, M.A.; KHAN, I.A.; CHEEMA, H.M.N.; RAJWANA, I.A.; KHAN, A.S.; KHAN, A.A. 2012. Extraction of DNA suitable for PCR applications from mature leaves of Mangifera indica L. J. Zhejiang University: Science B. (China). 13(4):239-243.

http://dx.doi.org/10.1631/jzus.B1100194

4. CAMARENA-TELLO, J.C.; MARTÍNEZ-FLORES, H.E.; GARNICA-ROMO, M.G.; PADILLA-RAMÍREZ, J.S.; SAAVEDRA-MOLINA, A.; M.C.; RODILES-LÓPEZ, J.O. 2018. Quantification of phenolic compounds and in vitro radical scavenging abilities with leaf extracts from two varieties of Psidium guajava L. Antioxidants. (Suiza). 7:34. https://doi.org/10.3390/antiox7030034

5. COTA, J.H.; REMARCHUK, K.; UBAYASENA, K. 2006. Ready-to-use DNA extracted with a CTAB method adapted for herbarium specimens and mucilaginous plant tissue. Plant Molecular Biology Reporter. (Estados Unidos). 24(2):161-167.

https://doi.org/10.1007/BF02914055

6. DESHMUKH, V.P.; THAKARE, P.V.; CHAUDHARI, U.S.; GAWANDE, P.A. 2007. A simple method for isolation of genomic DNA from fresh and dry leaves of Terminalia arjuna (Roxb.) Wight and Argot. Electronic J. Biotechnology. (Chile). 10(3):468-472.

https://doi.org/10.2225/vol10-issue3-fulltext-5

7. DOYLE, J.J.; DOYLE, J.L. 1987. A rapid DNA isolation procedure for small quantities of fresh leaf tissue. Phytochemical Bulletin. (Estados Unidos). 19:11-15.

8. FERREIRA, M.E.; GRATTAPAGLIA, D. 1998. Introducción al uso de marcadores moleculares en el análisis genético. Brasilia, BR, EMBRAPA. 220p.

9. GERSTEIN, A. 2001. Molecular Biology Problem Solver: A Laboratory Guide. ISBNs: 0-471-37972-7

10. HALOS, L.; JAMAL, T.; VIAL, L.; MAILLARD, R.; SUAU, A.; LE MENACH, A.; BOULOUIS, H.J.; VAYSSIERTAUSSAT, M. 2004. Determination of an efficient and reliable method for ADN extraction from ticks. Veterinary Research. (Reino Unido). 35:709-713. http://dx.doi.org/10.1051/vetres:2004038

11. KUMAR C.; KUMAR, R.; SINGH, S.; GOSWAMI, A.K.; PALIWAL, R.; SINGH, R. 2020. Development of novel g-SSR markers in guava (Psidium guajava L.) cv. Allahabad Safeda and their application in genetic diversity, population structure and cross species transferability studies. PLoS ONE. (Estados Unidos). 15(8): e0237538. https://doi.org/10.1371/journal.pone.0237538
12. KUMARI, S.; ARUMUGAM, N.; SINGH, R.; SRIVASTAV, M.; BANOTH, S.; MITHRA, A.C.; ARUN, M.B.; GOSWAMI, A.K.; KHAN, A.J. 2018. Diversity analysis of guava (Psidium guajava) germplasm collection. Indian J. Agr. Sciences. 88(3):489-497

13. MANNING, K. 1991. Isolation of nucleic acids from plants by differential solvent precipitation. Analytical Biochemistry. (Estados Unidos). 195:45-50. https://doi.org/10.1016/0003-2697(91)90292-2

14. MICHIELS, A.N.; VAN DEN ENDE, W.; VAN RIET, L.; VAN LAERE, A. 2003. Extraction of high-quality genomic DNA from latex-containing plants. Analytical Biochemistry. (Estados Unidos). 315(1):85-89. http:/ /dx.doi.org/10.1016/S0003-2697(02)00665-6

15. MILLER, R.G. 1996. Simultaneous Statistical Inference. McGraw-Hill. New York, 272p.

16. NARVÁEZ-CUENCA, C.E.; INAMPUES-CHARFUELAN, M.L.; HURTADO-BENAVIDE, A.M.; VINCKEN, J.P. 2020. The phenolic compounds, tocopherols, and phytosterols in the edible oil of guava (Psidium guava) seeds obtained by supercritical $\mathrm{CO}_{2}$ extraction. J. Food Composition and Analysis. (Estados Unidos). 89:103467.

http://dx.doi.org/10.1016/j.jfca.2020.103467

17. NERDO RODRÍGUEZ, N.; VALDÉS, J.; BECKER, D.; VELÁZQUEZ, B.; ROHDE, W. 2004. Aislamiento y purificación del ADN genómico del guayabo (Psidium guajava L.) para análisis molecular. Convención Trópico 2004. II Congreso de Agricultura Tropical. Palacio de Convenciones de La Habana, La Habana, Cuba. 6p.

18. PIPAN, B.; ZUPANČIČ M.M.; BLATNIK, E.; DOLNIČAR, P.; MEGLIČ, V. 2018. Comparison of Six Genomic DNA Extraction Methods for Molecular Downstream Applications of Apple Tree (Malus X domestica). Cogent Food Agriculture. (Estados Unidos). 4:1.

https://doi.org/10.1080/23311932.2018.1540094

19. RISTERUCCI, A.M.; DUVAL, M.F.; ROHDE, W.; BILLOTTE, N. 2005. Isolation and characterization of microsatellite loci from Psidium guajava L. Molecular Ecology Notes. (Reino Unido). 5(4):745-748. https://doi.org/10.1111/j.1471-8286.2005.01050.x

20. ROJAS, L.; PORTAL, O.; JIMÉNEZ, E. 2011. Extracción de ARN total en plantas y hongos filamentosos. Biotecnología vegetal. (Cuba). 11(4):213-222.

21. SAHU, S.K.; THANGARAJ, M.; KATHIRESAN, K. 2012. DNA extraction protocol for plants with high levels of 
secondary metabolites and polysaccharides without using liquid nitrogen and phenol. Molecular Biology. (Rusia). 6:1-6. https://doi.org/10.5402/2012/205049

22. SIKA, K.; KEFELA, T.; ADOUKONOU, H.; AHOTON, L.; SAIDOU, A.; BABA-MOUSSA, L.; GACHOMO, E. 2015. A simple and efficient genomic DNA extraction protocol for large scale genetic analyses of plant biological systems. Plant Gene. (Países Bajos). 1:43-45.

https://doi.org/10.1016/j.plgene.2015.03.001
23. SPSS. 2008. Statistical Package for Social Sciences Program. Version 17 for Windows, SPSS Inc., Chicago.

24. WHITEHOUSE, C.; HOT'TEL, H. 2007. Comparison of five commercial DNA extraction kits for the recovery of Francisella tularensis DNA from spiked soil samples. Molecular and Cellular Probes. (Estados Unidos). 21:92-96.

https://doi.org/10.1016/j.mcp.2006.08.003 